\title{
Defining risk factors for obstructive sleep apnea (OSA)
}

\author{
Palmira Alagyosova ${ }^{1}$, Laura Andreeva ${ }^{2}$
}

1. PhD assistant - Department of Orthodontics, Faculty of Dentistry, Medical University of Sofia;

2. PhD professor - Department of Orthodontics, Faculty of Dentistry, Medical University of Sofia;

\begin{abstract}
We have studied and found craniofacial characteristics in Bulgarian patients - men with OSA, with the aim to ease early diagnostics and we defined risk factors from the view point of dental medicine and orthodontics in order to find a probable anatomic protective factor to prevent the obstructive syndrome.

One hundred twenty three (123) facial side sciagraphy images of patients aged between 30 and 69 years have been made. 61 of them are individuals in good health, they form the control group, and 62 are patients diagnosed with OSA by means of polysomnography (PSG) represent the clinical patients' group.

Factors influencing OSA incidence have been found and quantitative assessment of their influence made as well. We have assessed the joint influence of factors related to a risk for OSA incidence. Upon applying of the Backward Conditional statistic proceeding, the final version confirmed three from the studied indices: distance between the sublingual bone $(H)$ and Spina nasalis posterior (PNS), sublingual bone $(H)$ and mandibular plane $(M P)$, tongue length $(V-T)$. We found that the distance between the sublingual bone $(H)$ and point $C 3$ (third cervical vertebra) - diminishes the risk of a complaint by appr. 24\% when increased by $1 \mathrm{~mm}$, i.e. it was found to be a protective factor. This suggested to us some therapeutic interventions in complaint cases - medializing of the lower jaw by apparatus (MAD-therapy). Meanwhile, it was an orientation for application of prophylactic means in growing orthodontic patients.
\end{abstract}

Keywords: Obstructive Sleep Apnea (OSA); Thickness of palate; Tongue height; Tongue length; 


\section{Introduction}

Obstructive Sleep Apnea (OSA) is a disease characterized by a repeating, temporary breathing interruption during the sleep as a result of upper respiratory tract closure for more than 10 seconds.

Anatomic indices have been found which could ease OSA diagnosing. These are related to specific ethnic characteristics, yet at the same time there are some general anatomic characteristics of individuals with a serious grade of OSA.

No comparative studies of the facial skeleton and the air ways in patients with OSA and/or clinically healthy individuals have been made in Bulgaria to date. We have defined craniofacial characteristics in Bulgarian patients - men with OSA, with the aim to ease early diagnostics, and we defined risk factors from the viewpoint of dental medicine and orthodontics, so that we could find a possible anatomic protective factor to prevent the obstructive syndrome.

\section{Aim}

The purpose is to define, and by means of cephalometric analysis statistically prove certain risk factors for OSA incidence.

\section{Material}

One hundred twenty three (123) facial side sciagraphy images of patients aged between 30 and 69 years have been made. 61 of them are individuals in good health, they form the control group, and 62 are patients diagnosed with OSA by means of polysomnography (PSG) represent the clinical patients' group.

Both the clinical and the control group have been concerted after sex, body mass index (BMI) and age.

\section{Results}

\section{Quantitative assessment of factors influencing OSA incidence.}

In order to find the factors influencing OSA incidence and to make the quantitative assessment of their effect we applied binary regression analysis (Tabular data 1 ).

In individual scheme significant are following factors:

- Thickness of palate - its increase by $1 \mathrm{~mm}$ rises the risk of OSA incidence by 2,2 times;

- Tongue length - its extension by $1 \mathrm{~mm}$ rises the rises the risk of OSA incidence by appr. 49\%;

- Tongue height - its increase by $1 \mathrm{~mm}$ rises the risk of OSA incidence by appr. 88\%; 
- Distance between the sublingual bone $(\mathrm{H})$ and point PNS of the hard palate - its increase by $1 \mathrm{~mm}$ rises the risk of OSA incidence by appr. 64\%;

- Distance between the sublingual bone $(\mathrm{H})$ and p. C3 (third cervical vertebra) - the risk drops by appr. $24 \%$ with its increase by $1 \mathrm{~mm}$, i.e. it was found to be a protective factor;

- Distance between the sublingual bone $(\mathrm{H})$ and the mandibular plane (MP) - its increase by $1 \mathrm{~mm}$ rises the risk for OSA incidence about 2 times.

In order to assess the joint influence of the factors related to the risk of OSA incidence, we applied a multiple logistic regression analysis. Upon application of the Backward Conditional statistical proceeding, in the final version of the equation remained three of the studies indices (Figure 1).

In a group scheme:

- Tongue length - this increased its risky effect to appr. 62\%;

- Distance between the sublingual bone $(\mathrm{H})$ and $\mathrm{p}$. PNS of the hard palate - this lowered its risky effect to appr. 42\%;

- Distance between the sublingual bone $(\mathrm{H})$ and the mandibular plane (MP) - this increased its risky effect up to appr. 2,2 times. 


\begin{tabular}{|c|c|c|c|c|c|c|c|c|c|}
\hline \multirow{3}{*}{ Index } & \multirow{3}{*}{ Comparison } & \multicolumn{4}{|c|}{ Individually } & \multicolumn{4}{|c|}{ In group } \\
\hline & & \multirow{2}{*}{ OR } & \multicolumn{2}{|c|}{$95 \%$ CI } & \multirow{2}{*}{$\mathrm{P}$} & \multirow{2}{*}{ OR } & \multicolumn{2}{|c|}{$95 \%$ CI } & \multirow{2}{*}{$\mathbf{p}$} \\
\hline & & & Lower limit & Upper limit & & & Lower limit & Upper limit & \\
\hline Palate thickness (mm) & Increase by 1 & 2,247 & 1,670 & 3,021 & $<0,001$ & & & & \\
\hline Tongue length (mm) & Increase by 1 & 1,489 & 1,268 & 1,749 & $<0,001$ & 1,625 & 0,997 & 2,649 & 0,051 \\
\hline Tongue height (mm) & Increase by 1 & 1,878 & 1,473 & 2,393 & $<0,001$ & & & & \\
\hline $\begin{array}{l}\text { Distance betw. sublingual bone }(\mathrm{H}) \text { and } \\
\text { p.PNS }{ }^{1} \text { of the hard palate }(\mathrm{mm})\end{array}$ & Increase by 1 & 1,639 & 1,373 & 1,955 & $<0,001$ & 1,422 & 1,141 & 1,772 & 0,002 \\
\hline $\begin{array}{l}\text { Distance betw. sublingual bone }(\mathrm{H}) \text { and } \\
\text { p.C3 (third cervical vertebra) (mm) }\end{array}$ & Decrease by 1 & 0,763 & 0,684 & 0,853 & $<0,001$ & & & & \\
\hline $\begin{array}{l}\text { Distance betw. sublingual bone }(\mathrm{H}) \text { and } \\
\text { (MP) mandibular plane (mm) }\end{array}$ & Increase by 1 & 2,019 & 1,562 & 2,609 & $<0,001$ & 2,224 & 1,390 & 3,558 & 0,001 \\
\hline
\end{tabular}

Tabular data 1: Relation of chances and 95\% CI (Confidence Interval) of the significant factors for OSA incidence

\begin{tabular}{|c|c|c|c|c|c|c|}
\hline Index & Threshold value & Sensitiveness & Specificity & $\begin{array}{l}\text { Positive predictable } \\
\text { value }\end{array}$ & $\begin{array}{c}\text { Negative predictable } \\
\text { value }\end{array}$ & Preciseness \\
\hline Palate thickness (mm) & $>10$ & 76 & 84 & 82 & 77 & 80 \\
\hline Tongue length (mm) & $>80$ & 92 & 43 & 62 & 84 & 67 \\
\hline Tongue height (mm) & $>39$ & 77 & 69 & 72 & 75 & 73 \\
\hline $\begin{array}{l}\text { Distance betw. sublingual bone }(\mathrm{H}) \text { and } \\
\text { p.PNS of the hard palate }(\mathrm{mm})\end{array}$ & $>66$ & 95 & 87 & 88 & 95 & 91 \\
\hline $\begin{array}{l}\text { Distance betw. sublingual bone }(\mathrm{H}) \text { and } \\
\text { p.C3 (third cervical vertebra) }(\mathrm{mm})\end{array}$ & $<37$ & 81 & 74 & 76 & 79 & 77 \\
\hline $\begin{array}{l}\text { Distance betw. sublingual bone }(\mathrm{H}) \text { and } \\
\text { (MP) mandibular plane }(\mathrm{mm})\end{array}$ & $>15$ & 94 & 87 & 88 & 93 & 90 \\
\hline
\end{tabular}

Tabular data 2: Threshold values of indices having effect on OSA incidence and assessment of validation criteria 
Threshold values of indices influencing OSA incidence and assessment by means of validation criteria values

In order to find threshold values of the indices which influence OSA incidence we applied the ROC curve analysis, where the results show in Fig. 1 to 6 . In the enclosed figures it can be seen that:

- The biggest area under the curve has the index „Distance between the sublingual bone (H) and p. PNS“ (0,965, Fig. 1), followed by „Distance between the sublingual bone (H) and (MP) the mandibular plane" $(0,956$, Fig. 2$)$; followed by the index „Thickness of the hard palate" $(0,857$, Fig. 3); the index „Tongue height" (0,823, Fig.4); „Distance between the sublingual bone $(\mathbf{H})$ and $\mathrm{C} 3$ (third cervical vertebra)" (0,821, Fig. 5)

- The index tongue length occupies the smallest area (0,787, Fig. 6).

The figures have been shown in descending order after results obtained of the studied indices.

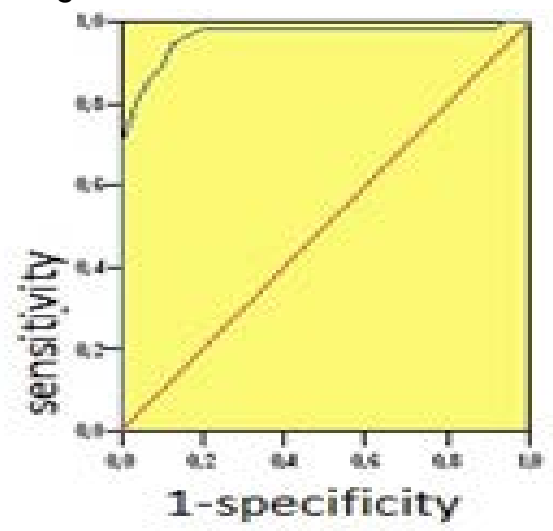

Figure 1: ROC curve of the index distance between the sublingual bone $(\mathrm{H})$ and $p$. PNS of the hard palate (area under the curve $0,965, p<0,001$ )

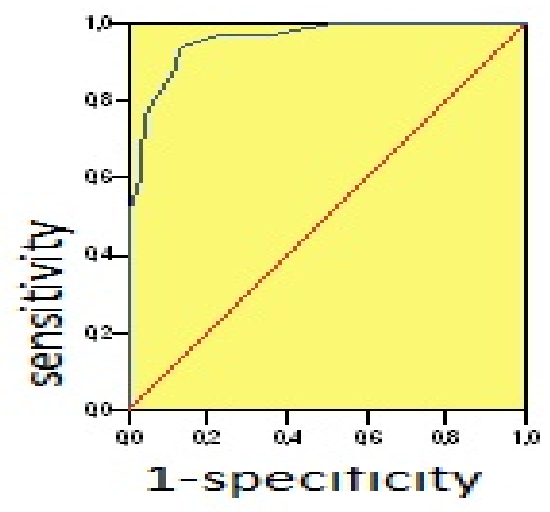

Figure 2: ROC curve of the index distance between the sublingual bone $(H)$ and $(M P)$ the mandibulare plane -(area under the curve 0,956, $p<0,001$ ) 


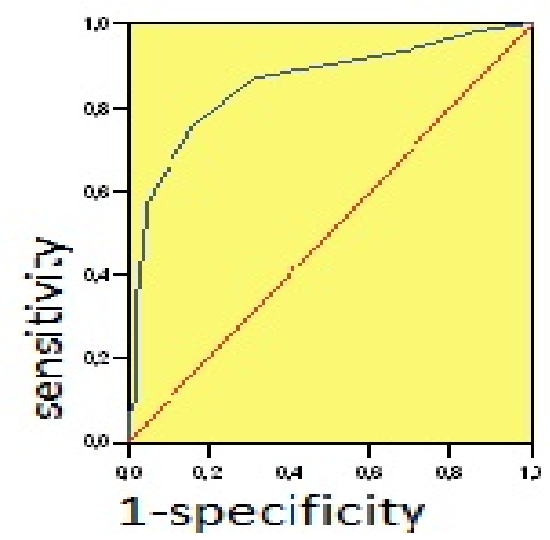

Figure 3: ROC curve of the index thickness of the soft palate (area under the curve $0,857, p<0,001$ )

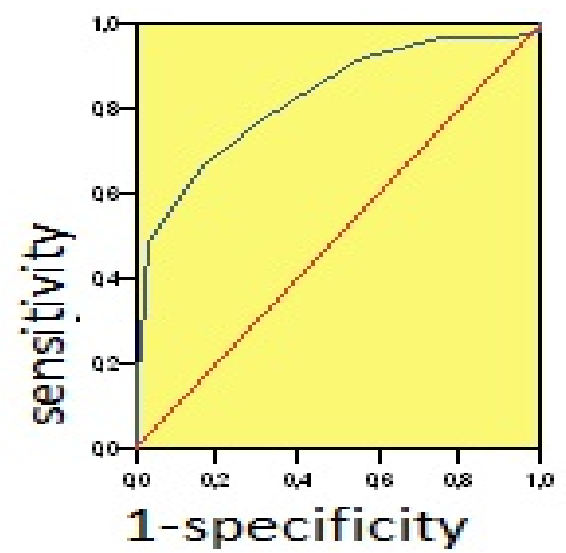

Figure 4: ROC curve of the index tongue height (area under the curve $0,823, p<0,001$ )

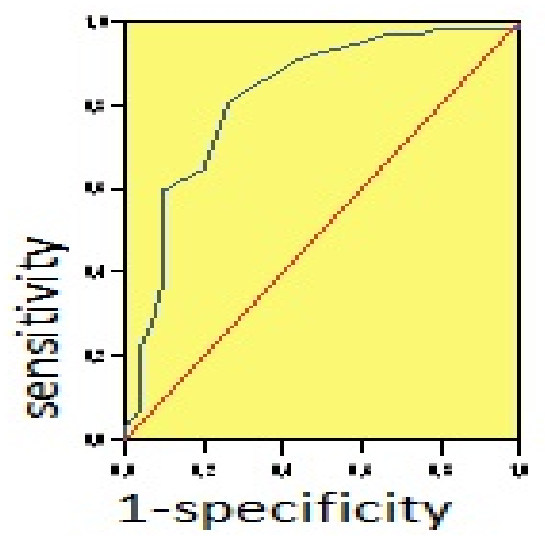

Figure 5: ROC curve of the index distance between the sublingual bone $(\mathrm{H})$ and p.C3 (third cervical vertebra) (area under the curve $0,821, p<0,001$ ) 


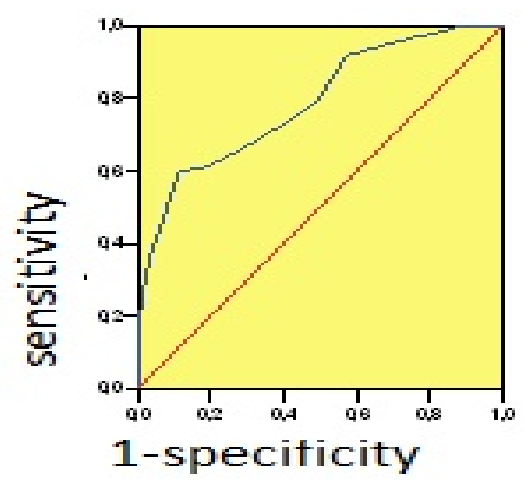

Figure 6: ROC curve of the index tongue length (area under the curve $0,787, p<0,001$ )

In Tabular Data 2 it can be seen that the best assessed validation criteria have following indices: distance between the sublingual bone $(\mathrm{H})$ and p.PNS of the hard palate, followed by the distance between the sublingual bone $(\mathrm{H})$ and $(\mathrm{MP})$ the mandibular plane (MP), where the lowest assessment rate is that of the index tongue length.

\section{Discussion}

Cephalometric x-ray analysis is applied to obtain an assessment of hard and soft tissue structures in patients with OSA(12) thus finding also craniofacial risk factors, which could, alongside with the mechanism of the upper air compliance1 (stability) and the muscle function play an essential role in the etiology of OSA $(17,8,9,3,10,7,6)$.

The etiology of OSA still has not been well clarified. It is possible that the presence of the hereditary component could be based in the facial skeleton development, the form and the volume of the pharynx and the soft tissues. Specific characteristics in facial and pharyngeal morphology and physiology like enlarged tonsils and uvula, macroglossia, size and position of the maxilla and of the mandibula are closely related to the arising of preconditions for an OSA development after a given age $(2,11,18)$.

In the OSA etiopathogenesis take part central mechanisms related to regulation of muscle tonus during the sleep. The serotonin (5-HT) participation as a stimulant of dilatation of the pharynx walls has been proven. During a sleep the activity of serotonin transmission to dilating muscles drops down, so beyond a certain limit this causes an occlusion, respectively apnea (hypopnea). During the sleep the pharyngeal muscles tonus decreases, the tongue muscles m.genioglosus and m.geniohyoideus relax and all this leads to a collapse of the tongue root. $M$. tensor vely palatini does not support the tonus and the inclination of the pathologically extended soft palate - all this causes constriction or total obstruction of the pharynx lumen $(13,14)$.

\section{Risk factors: sex, obesity, muscle relaxation}

Craniofacial anatomic peculiarities: a greater part of the OSA patients who were examined and the respective findings analysed were obese men $\mathrm{BMI}(\overline{\mathrm{X}}=30,6)$, middle-aged and having craniofacial peculiarities $(\bar{X}=49,10)$. As a whole, the facial skeleton is reduced in depth due to a shortened cranial 
base, maxilla and mandibula. More patients in the OSA group (63\%) have micrognathia of the lower jaw. There are proofs sustaining the hypothesis that a distal positioned small lower jaw and a diminished space between the spine and its corpus could cause a rear positioning of the tongue and a horizontal inclination of the soft palate, thus increasing the risks for worsening of the respiratory function and causing breathing problems during sleep $(5,7)$.

We obtained results supporting this hypothesis. The distance between the sublingual bone and the third cervical vertebra- $\mathrm{H}-\mathrm{C} 3(\mathrm{P}<0,001)$ is smaller in OSA-patients. (Tabular data 1$)$

An OSA model has been made in which the grade of craniocervical anomalies in patients was correlated to an obesity grade - a critical BMI which shall cause OSA incidence.

Anatomic factors (soft tissues and pharynx) as an obstruction cause: Usually, obstruction is nasopharyngeal or oropharyngeal. Anatomic factors which could lead to it are a hypertrophy of soft tissues, a big tongue, a long soft palate. We have found that the oral cavity is occupied by $3 \%$ more by a tongue with a longer sagittal size; higher and with a bigger area in the OSA Group, and also pulled in caudal direction to the hypopharynx. We found also a lower positioning of the sublingual bone in the OSA - patients. This fact supports the hypothesis that an extended pharynx is more susceptible to the mechanic impact of the inspirational air pressure13. The height and the cross size are pathologically changed in patients with OSA $(15,16)$. The capability of the muscles to pull the lateral walls of the pharynx is favouring the force of its resistance against changing air pressure. Yet their ability to resist diminishes with axial extension and the aging of the tissues. Our results support this hypothesis.

The significant differences in the sagittal sizes of the pharynx between the two groups give us the reason to sustain the hypothesis, that anatomic constrictions probably cause obstructions during the sleep. We have applied the method after Tangugsorn V, Skatvedt O., Krogstad, O. Lyberg, T15 (Fig. 7).

Areas of:

1. Tongue (TA) -light gray;

2. Soft palate (SPA) - black;

3. Oral cavity (OA) - light gray, white and black;

4. Pharyngeal area (PhA) - dark gray;

5. Oropharingeal area (OPA) - light gray, white, black, dark gray

(figure Ama Johal)

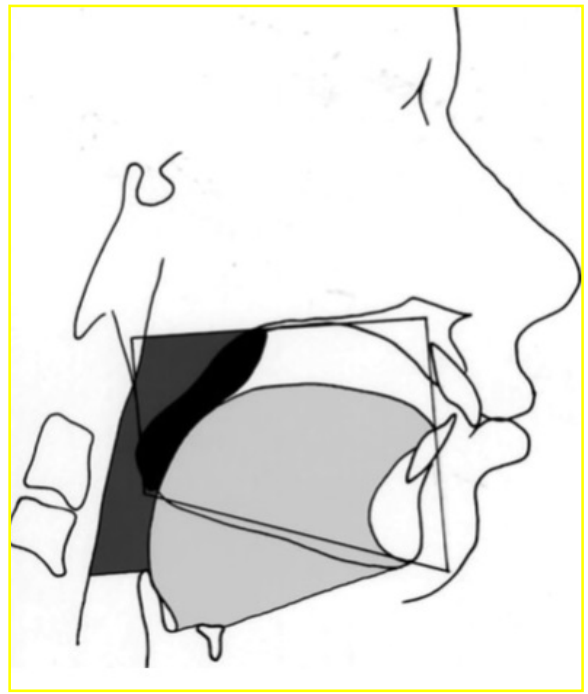

Figure 7: Areas of anatomic structures 
We have found a change in the relation tongue area and oral cavity (TA/O), as well as a diminished area of the pharynx [(TA+SPA)/OPA] due to increased sagittal dimensions of the tongue (TA) and the soft palate (SPA) (15).

This is a serious challenge for the pharynx muscles to cope with the requirement to enable the air way passability especially during the sleep, when they are relaxed. The ageing muscle changes (muscle strength) have to be taken into account too, wherefrom a greater mechanic work performed by the muscles to overcome the resistance, i.e. a reduced compensatory possibility in the presence of anatomic changes of the soft tissues in the oral cavity.

\section{Conclusion}

- By means of statistical methods of analysis we found the factors having an impact on OSA incidences in the clinical group.

- We could assess the combined impact of the factors related to risk for OSA incidence. We made a quantitative assessment of the evidenced factors.

- Upon application of the Backward Conditional statistical proceeding three of the studied indices (distances) remained in the final version, between:

a) sublingual bone $(\mathrm{H})$ and $\mathrm{p}$. PNS,

b) sublingual bone $(\mathrm{H})$ and mandibular plane $(\mathrm{MP})$,

c) tongue length $(\mathrm{V}-\mathrm{T})$.

We found that the distance between the sublingual bone $(\mathrm{H})$ and p.C3 (third cervical vertebra) decreases the risk of an incidence by appr. $24 \%$ when extended by $1 \mathrm{~mm}$, i.e. this appears to be a protective factor. This evidence gives us a direction for certain therapeutic approaches to affect a stated disease medializing the lower jaw by means of apparatuses (MAD therapy). At the same time, it is an orientation towards applying prophylactic measures in growing orthodontic patients.

\section{References}

1. Nachev N.D., Penchev A. Physiologye, Medicine I Gymnastics, 1989

2. Behlfelt $\mathrm{K}$, Linder-Aronson $\mathrm{S}$, et al. Cranio-facial morphology in children with and without enlarged tonsils. Eur J Orthod, 1990b; 12: 458-67;

3. de Berry-Borowiecki B, Sassin J E 1983 Surgical treatment of sleep apnea. Archives of Otolaryngology, 1997, 508-512;

4. Demsey JA, Veasey SC. Phatophysiology of sleep apnea. Physiol Rev, 2010, 90 (2): 797-8;

5. Guilleminault $\mathrm{C}$, Chowdhuri S. Upper airway resistance syndrome is a distinct syndrome. Am J Respir Crit Care Med., 2000; 161: 1412-1416;

6. Guilleminault $C$, Stoohs R, Clerk A, et al. A cause of daytime sleepiness: the upper airway resistance syndrome. Chest., 1993; 104: 781-87;

7. Lowe, A A., Ozbek, M M., Miyamoto, K., Pae, E K. and Fleetham, J A. Cephalometric and demographic characteristics of obstructive sleep apnea: an evaluation with partial least squares. Angle Orthod., 1997, 67: 143-154; 
8. Lowe, A. A., Gionhaku N, Takuechi K, Fleetham A J., Three-dimensional C T reconstructions of tongue and airway in adult subjects with OSA. Am J of Orthod and Dentofacial Orthopedics, 1986, 90: 364-374;

9. Pae E-K, Lowe AA, Fleetham JA. A role of pharyngeal length in obstructive sleep apnea patients. Am J Orthod Dentofacial Orthop., 1997; 111: 12-17;

10. Partinen M, Guilleminault C, Quera-Salva MA, Jamieson A. Obstructive sleep apnea and cephalometric roentgenograms: the role of anatomic upper airway abnormalities in the definition of abnormal breathing during sleep. Chest., 1988; 93: 1199-1205;

11. Sommerville JM. et al. Morphology of the submental and neck region. Int. J. Adult. Orthod., 1988; 3: $97-106$;

12. Srezlow V, Blanks N I, Berile A., Cephalometric airway analysis in OSAS. Laryngoscope, 1988, 98: 1149-1158;

13. Talmant J, Stephane Renaudin, Pascal Renaud. Ventilation and mechanics of the oropharinx. Rev Orthop Dento Faciale, 1998, 32: 105-166;

14. Talmant J, Renaudin St. Ventilation et mecanique des tissues mous faciaux Rev Orthop Dento Faciale, 1996, 30: 253-269;

15. Tangugsorn, V, Skatvedt O., Krogstad, O. Lyberg, T. Obstructive sleep apnoea: a cephalometric study. Part II. Uvulo-glossopharyngeal morphology. Eur. J. Orthod., 1995, 17: 57-67;

16. Tourne LPM. Growth of the pharynx and its physiologic implications. Am J Orthod Dentofacial Orthop., 1991; 99: 129-139;

17. Tsuchiya M, Lowe AA, Pae EK, Fleetham JA. Obstructive sleep apnea subtypes by cluster analysis. Am J Orthod Dentofacial Orthop., 1992;101: 533-542;

18. Vig KW. Nasal obstruction and facial growth: the strength of evidence for clinical assumptions. Am J Orthod Dentofacial Orthop, 1998; 113: 603-611.

\section{Corresponding author:}

Laura Andreeva, PhD professor

Department of Orthodontics,

Faculty of Dentistry,

Medical University of Sofia 